\title{
Pengujian Black Box pada Aplikasi Sistem Seleksi Pemenang Tender Menggunakan Teknik Equivalence Partitions
}

\author{
Aini Arifta Arwaz ${ }^{1}$, Kurnia Putra ${ }^{2}$, Rediansyah Putra ${ }^{3}$, Theja Kusumawijaya ${ }^{4}$, Aries \\ Saifudin ${ }^{5}$ \\ Teknik Informatika, Universitas Pamulang, Tangerang Selatan, Banten, Indonesia \\ E-mail: ${ }^{1}$ ainiarifta@gmail.com, ${ }^{2}$ kurniaputra027@gmail.com, ${ }^{3}$ redip2308@gmail.com, \\ thejakusuma33@gmail.com, 5aries.saifudin@unpam.ac.id
}

\begin{abstract}
The tender winner selection system is important to ensure the winner will complete the project well. If there is a selection error that caused the project to fail, the application must be tested and error free. Testing in this study uses Black Box Testing. The Black Box Testing Method consists of several methods including Equivalence Partitions, Boundary Value Analysis, Comparison Testing, Sample Testing, Robustness Tesing, and others. Among the many methods of testing, in this study the method of testing Equivalence Partitions was chosen. The purpose of the Equivalence Partitions method is to look for errors in functions that are wrong or missing, errors in the interface, errors in data structures or database access, performance errors, initialization errors and final destinations. Based on the test results show there are still many shortcomings when validating data to be entered, so that it can cause data stored in the database does not match the expected data.
\end{abstract}

Keywords: Black Box; Equivalence Partitions; Selection System; Tender Winner; Testing

Abstrak

Sistem seleksi pemenang tender penting untuk memastikan pemenang akan menyelesaikan proyek dengan baik. Jika ada kesalahan pemilihan dapat menyebabkan kegagalan proyek, aplikasi ini harus teruji dan bebas kesalahan. Sehingga pada penelitian ini diterapkan pengujian perangkat lunak dengan menggunakan teknik Black Box Testing. Metode Black Box Testing terdiri atas beberapa cara antara lain Equivalence Partitions, Boundary Value Analysis, Comparison Testing, Sample Testing, Robustness Tesing, dan lain-lain. Diantara sekian banyak cara pengujian tersebut, pada penelitian ini dipilih cara pengujian Equivalence Partitions. Tujuan metode Equivalence Partitions untuk mencari kesalahan pada fungsi yang salah atau hilang, kesalahan pada interface, kesalahan pada struktur data atau akses database, kesalahan performansi, kesalahan inisialisasi dan tujuan akhir. Berdasarkan hasil pengujian menunjukkan bahwa masih terdapat banyak kekurangan saat melakukan validasi data yang akan dimasukkan, sehingga dapat menyebabkan data yang disimpan pada database tidak sesuai dengan data yang diharapkan.

Kata Kunci: Black Box; Equivalence Partitions; Pemenang Tender; Pengujian; Sistem Seleksi

\section{Pendahuluan}

Pengujian adalah sekumpulan langkah di mana dapat menempatkan rancangan khusus uji coba yang spesifik serta sekumpulan kegiatan yang direncanakan dan teratur untuk menguji atau menilai kebenaran yang diinginkan aktifitas pengujian (Cholifah, Sagita, \& Yulianingsih, 2018).

Dalam menjalankan pekerjaan proyek dibutuhkan proses seleksi untuk memilih pemenang tender yang berkualitas dan dipercaya. Suatu rangkaian proyek yang diselenggarakan pemerintah maupun lembaga swasta mengatakan bahwa seleksi pemenang tender sangat penting. Sebab, pada saat seleksi tersebut panitia seleksi dapat menilai kualitas setiap peserta. Untuk memastikan pemenang tender yang benar-benar berkualitas dan dapat dipercaya, panitia seleksi harus bersifat transparan dalam proses seleksi pemenang tender (Nursetyo, 2016). Pada aplikasi Sistem Seleksi Pemenang Tender ini bertujuan untuk menghasilkan keluaran yang dapat memberikan pertimbangan kepada manajemen untuk menentukan tender terbaik ini menggunakan 
metode Weighted Product (WP). Hasil dari penggunaan metode Weight Product (WP) dalam aplikasi Sistem Seleksi Pemenang Tender ini dapat memberikan sebuah pertimbangan bagi penyelenggara seleksi pemenang tender dalam pengambilan keputusan untuk penentuan pemilihan pemenang terbaik sehingga aplikasi Sistem Seleksi Pemenang Tender ini layak digunakan sebagai bahan pertimbangan dalam pengambilan keputusan (Dona, Yasdomi, \& Urfi, 2018).

Pengujian perlu dilakukan untuk memastikan sistem seleksi pemenang tender bebas dari kesalahan. Test Case dipersiapkan terlebih dahulu sebelum dilakukannya pengujian untuk memperoleh kemungkinan tertinggi untuk menemukan kesalahan dengan waktu dan usaha yang minimun. Perancangan Test Case terdri dari beberapa teknik pengujian yaitu Black Box Testing dan White Box Testing (Lumbanraja, 2017) . Pada pengujian perangkat lunak ini mengusulkan metode Black Box Testing. Metode Black Box Testing yaitu pengujian yang memfokuskan keperluan fungsional dari perangkat lunak, sehingga penguji dapat mendefinisikan kumpulan kondisi masukan yang valid dan menentukan keluaran benar pada spesifikasi perangkat lunak (Hidayat \& Muttaqin, 2018). Black Box Testing bukan merupakan alternatif dari White Box Testing, tetapi Black Box Testing yang melengkapi untuk menemukan kesalahan lainnya yang tidak dicakup oleh White Box Testing. Terdapat beberapa kategori dalam menemukan kesalahan pada Black Box Testing yaitu fungsi-fungsi yang salah atau hilang, kesalahan interface, kesalahan struktur data atau akses database eksternal, kesalahan performa dan kesalahan inisialisasi atau terminasi (Mustaqbal, Firdaus, \& Rahmadi, 2015).

Pengujian Black Box menggunakan teknik Equivalence Partitions merupakan pengujian berdasarkan masukan setiap menu yang terdapat pada sistem seleksi pemenang tender, setiap menu masukan dilakukan pengujian melalui klasifikasi dan pengelompokan berdasarkan fungsinya (Hidayat \& Muttaqin, 2018). Teknik Equivalence Partitions untuk menggambarkan masukkan keadaan valid atau tidak. Sehingga dari cara pengujian sudah dijelaskan untuk melakukan pengujian dari teknik Equivalence Partitions yang nantinya akan di implementasikan pada sistem informasi tersebut, dapat diketahui hasil pada bab selanjutnya.

\section{Metodologi}

Tujuan dari pengujian adalah untuk memastikan bahwa sistem yang dihasilkan sesuai dengan kebutuhan dan layak untuk digunakan. Metode Black Box Testing yang digunakan pada pengujian ini bertujuan untuk menampilkan pesan kesalahan pada sistem aplikasi jika terjadi kesalahan dan fungsi yang tidak benar atau hilang dalam memasukan data (Ferdinandus, Wowor, \& Lumenta, 2012). Black Box Testing sendiri merupakan pengujian perangkat lunak yang menguji fungsionalitas aplikasi yang bertentangan dengan struktur internal atau kerja (Syaban \& Syaban, 2015). Jenis pengujian pada metode Black Box Testing yaitu Black Box yaitu Equivalence Partitions, Boundary Value Analysis/Limit Testing, Comparison Testing, Sample Testing, Robustness Testing, Behavior Testing, Performance Testing, Requirement Testing, Endurance Testing dan Cause - Effect Relationship Testing (Hanifah, Alit, \& Sugiarto, 2016).

Pengujian menggunakan masukan data acak bertujuan untuk memastikan sistem menolak untuk menyimpan data masukan pada database, sehingga sistem dikatakan layak untuk digunakan (Hanifah, Alit, \& Sugiarto, 2016). Dalam penelitian ini akan dilakukan beberapa tahapan. Pada tahapan pertama diawali dengan menentukan Test Case perangkat lunak yang akan diuji dengan teknik Equivalence Partitions kemudian menginisialisasi standar grade partition masukan dan keluaran. Hal ini dilakukan untuk mendapatkan dataset berupa dokumentasi pengujian dengan metode Equivalence Partitions dan nilai tingkat efektifitas metode Equivalence Partitions (Komarudin, 2016).

Pada hasil pengujian terdapat tabel rancangan Test Case yang berfungsi untuk menyimpulkan apakah sistem berhasil dalam pengujian tipe tersebut atau tidak. Rancangan Test Case berdasarkan Equivalence Partitions ditunjukkan pada tabel 1, tabel 2 dan tabel 3. 


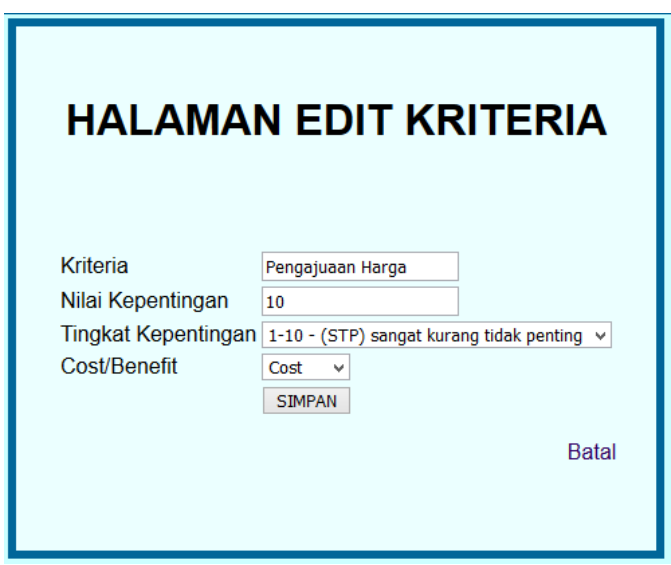

Gambar 1 Form Edit Kriteria

Berdasarkan form pada Gambar 1 terdapat beberapa rencana pengujian. Pada rencana pengujian Kriteria data akan valid jika Kriteria harus diisi dengan memasukkan abjad (contohnya "abc") yang terdiri dari 20 digit dan tidak boleh kosong. Begitupun sebaliknya data akan tidak valid jika Kriteria diisi dengan memasukkan angka (contoh "123") atau lebih dari 20 digit. Pada rencana pengujian Nilai Kepentingan data akan valid jika Nilai Kepnetingan diisi dengan memasukkan angka (contohnya "123") yang terdiri dari 3 digit dan tidak boleh kosong. Begitupun sebaliknya data akan tidak valid jika Nilai Kepentingan diisi dengan memasukkan huruf (contoh "abc") atau lebih dari 3 digit.

Tabel 1Rancangan Test Case Form Edit Kriteria

\begin{tabular}{|l|l|l|}
\hline Id & Deskripsi Pengujian & Hasil Yang Diharapkan \\
\hline A01 & $\begin{array}{l}\text { Mengisi Kriteria dengan "Pengajuan Harga" } \\
\text { dan Nilai Kepentingan dengan "10" kemudian } \\
\text { klik tombol SIMPAN }\end{array}$ & $\begin{array}{l}\text { Sistem mampu menyimpan data kedalam database dan } \\
\text { mengalami perubahan tampilan pada sistem }\end{array}$ \\
\hline A02 & $\begin{array}{l}\text { Mengisi Kriteria dengan "abc123" atau "123" } \\
\text { atau tidak diisi dan Nilai Kepentingan dengan } \\
\text { "1000" atau "abc" kemudian klik tombol } \\
\text { SIMPAN }\end{array}$ & Sistem menolak untuk menyimpan data \\
\hline
\end{tabular}

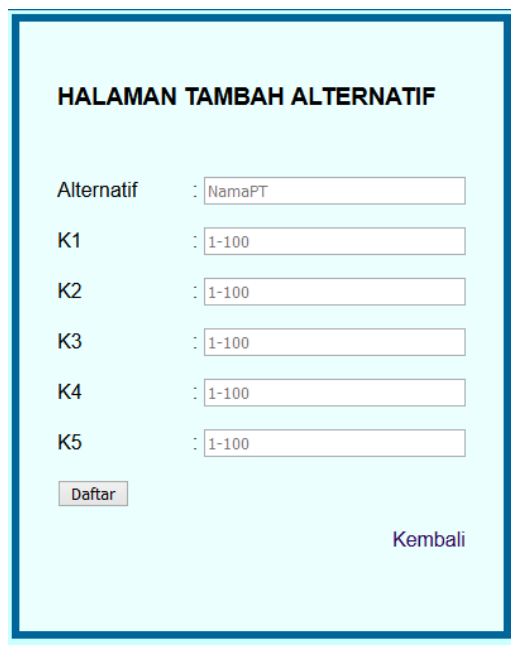

Gambar 2 Form Tambah Alternatif
Berdasarkan form pada Gambar 2 terdapat beberapa rencana pengujian. Pada rencana pengujian Alternatif data akan valid jika Alternatif harus diisi dengan memasukkan abjad (contohnya "abc") yang terdiri dari 30 digit dan tidak boleh kosong. Begitupun sebaliknya data akan tidak valid jika Alternatif diisi dengan memasukkan angka (contoh "123") atau lebih dari 30 digit. Pada rencana pengujian K1, K2, K3, K4 dan K5 data akan valid jika Nilai Kepnetingan diisi dengan memasukkan angka (contohnya "123") yang terdiri dari 3 digit dan tidak boleh kosong. Begitupun sebaliknya data akan tidak valid jika $\mathrm{K} 1, \mathrm{~K} 2, \mathrm{~K} 3, \mathrm{~K} 4$ dan K5 diisi dengan memasukkan huruf (contoh "abc") atau lebih dari 3 digit.

Tabel 2 Rancangan Test Case Form Tambah Alternatif

\begin{tabular}{|l|l|l|}
\hline Id & Deskripsi Pengujian & Hasil Yang Diharapkan \\
\hline B01 & $\begin{array}{l}\text { Mengisi Alternatif dengan "PT Sumber Jaya } \\
\text { Abadi" dan K1, K2, K3, K4, K5 dengan “100” } \\
\text { kemudian klik tombol daftar }\end{array}$ & Sistem berhasil menerima penambahan data \\
\hline B02 & $\begin{array}{l}\text { Mengisi Alternatif dengan "abc123" atau } \\
\text { "123" atau tidak diisi dan K1, K2, K3, K4, K5 } \\
\text { dengan "1000" kemudian klik tombol daftar }\end{array}$ & Sistem menolak untuk menyimpan data \\
\hline
\end{tabular}




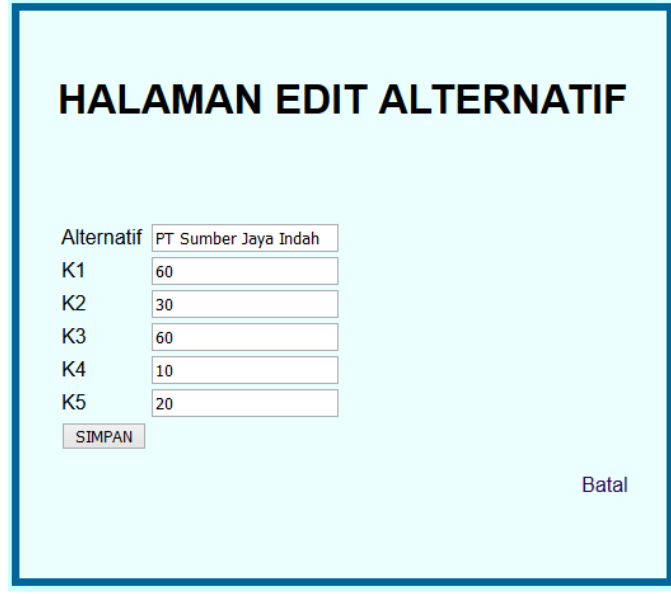

Gambar 3 Form Edit Alternatif
Berdasarkan form pada Gamabr 3 terdapat beberapa rencana pengujian. Pada rencana pengujian Alternatif data akan valid jika Alternatif harus diisi dengan memasukkan abjad (contohnya "abc") yang terdiri dari 30 digit dan tidak boleh kosong. Begitupun sebaliknya data akan tidak valid jika Alternatif diisi dengan memasukkan angka (contoh "123") atau lebih dari 30 digit. Pada rencana pengujian K1, K2, K3, K4 dan K5 data akan valid jika Nilai Kepnetingan diisi dengan memasukkan angka (contohnya "123") yang terdiri dari 3 digit dan tidak boleh kosong. Begitupun sebaliknya data akan tidak valid jika $\mathrm{K} 1, \mathrm{~K} 2, \mathrm{~K} 3, \mathrm{~K} 4$ dan K5 diisi dengan memasukkan huruf (contoh "abc") atau lebih dari 3 digit.

Tabel 3 Perancangan Test Case Form Edit Alternatif

\begin{tabular}{|l|l|l|}
\hline Id & Deskripsi Pengujian & Yang diharapkan \\
\hline C01 & $\begin{array}{l}\text { Mengisi Alternatif dengan "PT Sumber Jaya } \\
\text { Abadi" dan K1, K2, K3, K4, K5 dengan "100" } \\
\text { kemudian klik tombol SIMPAN }\end{array}$ & $\begin{array}{l}\text { Sistem mampu menyimpan data kedalam database dan } \\
\text { mengalami perubahan tampilan pada sistem. }\end{array}$ \\
\hline C02 & $\begin{array}{l}\text { Mengisi Alternatif dengan "abc123" atau } \\
\text { "123" atau tidak diisi dan K1, K2, K3, K4, K5 } \\
\text { dengan "1000" kemudian klik tombol } \\
\text { SIMPAN }\end{array}$ & Sistem menolak untuk menyimpan data \\
\hline
\end{tabular}

\section{Hasil dan Pembahasan}

Tabel 4 Rencana Pengujian

\begin{tabular}{|c|c|c|c|c|}
\hline Id & Deskripsi Pengujian & Yang diharapkan & Hasil Pengujian & Kesimpulan \\
\hline A01 & $\begin{array}{l}\text { Mengisi Kriteria dengan } \\
\text { "Pengajuan Harga" dan Nilai } \\
\text { Kepentingan dengan "10" } \\
\text { kemudian klik tombol SIMPAN }\end{array}$ & $\begin{array}{l}\text { Sistem mampu menyimpan } \\
\text { data kedalam database dan } \\
\text { mengalami perubahan } \\
\text { tampilan pada sistem }\end{array}$ & $\begin{array}{l}\text { Tampilan halaman } \\
\text { utama aplikasi Sistem } \\
\text { Seleksi Pemenang } \\
\text { Tender }\end{array}$ & Sesuai \\
\hline A02 & $\begin{array}{l}\text { Mengisi Kriteria dengan } \\
\text { "abc123" atau "123" atau tidak } \\
\text { diisi dan Nilai Kepentingan } \\
\text { dengan "1000" atau "abc" } \\
\text { kemudian klik tombol SIMPAN }\end{array}$ & $\begin{array}{l}\text { Sistem menolak untuk } \\
\text { menyimpan data }\end{array}$ & $\begin{array}{l}\text { Tampilan pesan } \\
\text { peringatan data tidak } \\
\text { lengkap }\end{array}$ & Sesuai \\
\hline B01 & $\begin{array}{l}\text { Mengisi Alternatif dengan "PT } \\
\text { Sumber Jaya Abadi" dan K1, } \\
\text { K2, K3, K4, K5 dengan " } 100 " \\
\text { kemudian klik tombol daftar }\end{array}$ & $\begin{array}{l}\text { Sistem berhasil menerima } \\
\text { penambahan data }\end{array}$ & $\begin{array}{l}\text { Tampilan data kriteria } \\
\text { dan alternatif }\end{array}$ & Sesuai \\
\hline B02 & $\begin{array}{l}\text { Mengisi Alternatif dengan } \\
\text { "abc123" atau "123" atau tidak } \\
\text { diisi dan K1, K2, K3, K4, K5 } \\
\text { dengan " } 1000 " \text { kemudian klik } \\
\text { tombol daftar }\end{array}$ & $\begin{array}{l}\text { Sistem menolak untuk } \\
\text { menyimpan data }\end{array}$ & $\begin{array}{l}\text { Tampilan pesan } \\
\text { peringatan data tidak } \\
\text { lengkap }\end{array}$ & Sesuai \\
\hline C01 & $\begin{array}{l}\text { Mengisi Alternatif dengan "PT } \\
\text { Sumber Jaya Abadi" dan K1, } \\
\text { K2, K3, K4, K5 dengan "100" } \\
\text { kemudian klik tombol SIMPAN }\end{array}$ & $\begin{array}{l}\text { Sistem mampu menyimpan } \\
\text { data kedalam database dan } \\
\text { mengalami perubahan } \\
\text { tampilan pada sistem. }\end{array}$ & $\begin{array}{l}\text { Tampilan data kriteria } \\
\text { dan alternatif }\end{array}$ & Sesuai \\
\hline $\mathrm{C} 02$ & $\begin{array}{l}\text { Mengisi Alternatif dengan } \\
\text { "abc123" atau "123" atau tidak } \\
\text { diisi dan K1, K2, K3, K4, K5 } \\
\text { dengan "1000" kemudian klik } \\
\text { tombol SIMPAN }\end{array}$ & $\begin{array}{l}\text { Sistem menolak untuk } \\
\text { menyimpan data }\end{array}$ & $\begin{array}{l}\text { Tampilan pesan } \\
\text { peringatan data tidak } \\
\text { lengkap }\end{array}$ & Sesuai \\
\hline
\end{tabular}


Berdasarkan rencana pengujian yang telah disusun, selanjutnya dilakukan penerapan pengujian. Hasil dari pengujian yang dilakukan ditunjukkan pada Tabel 4.

Jumlah Form yang diuji 5 form dengan form login diuji sebanyak $1 \mathrm{kali}$, form daftar login diuji sebanyak $1 \mathrm{kali}$, form edit kriteria diuji sebanyak 1 kali, form alternatif diuji sebanyak 10 kali dan form edit alternatif diuji sebanyak 1 kali. Jadi, total pengujian ada 14 kali. Jumlah form yang ditemukan adanya error atau bug pada proses pengujian fungsional. Untuk menjaga kestabilan fungsi dari perangkat lunak ini maka diperlukan prosedur penggunaan dan batasan pengguna yang jelas. Sehingga dapat memberikan gambaran bagaimana serangkaian skenario diujikan untuk memperoleh nilai yang valid, sehingga hasil masukkan sesuai dengan yang diinginkan.

\section{Kesimpulan}

Berdasarkan pada hasil perolehan pengujian telah dibahas, dapat diambil kesimpulan bahwa pengujian dengan menggunakan metode Black Box Testing memberikan pengumpulan hasil pengujian yang memberikan informasi sesuai perangkat lunak yang diuji sehingga dapat berjalan dengan sebagaimana mestinya dan telah memenuhi standar faktor kualitas fungsional.. Teknik pengujian Equivalance Partitions dapat membantu proses pembuatan kasus pengujian dan membuat pengujian lebih sederhan dan fungsi entri data perlu dilengkapi dengan beberapa proses validasi data untuk menjamin ketepatan entri data sesuai fungsional yang diinginkan.

\section{Saran}

Berdasarkan proses pengujian dan hasil pembahasan pengujian peragkat lunak Sistem Seleksi Pemenang Tender masih perlu untuk kembangkan. Adapun saran untuk pengembangan aplikasi berikutnya yaitu menggunakan metode selanjutnya degan metode White Box Testing agar dapat mengetahui setiap detail perancangan dari pembuatan struktur perangkat lunak ini, serta dapat mencoba teknikteknik pengujian Black Box Testing lainnya agar mengetahui kualitas perangkat lunak jauh lebih untuk menemukan kesalahan.

\section{Referensi}

Cholifah, W. N., Sagita, S. M., \& Yulianingsih. (2018). Pengujian Black Box Testing pada Aplikasi Action \& Strategy Berbasis Android dengan Teknologi Phonegap. Jurnal STRING (Satuan Tulisan Riset dan Inovasi Teknologi), 3(2), 206-210.

Dona, Yasdomi, K., \& Urfi, U. (2018). Sistem Pendukung Keputusan Karyawan Terbaik Menggunakan Metode Weight Product (WP) (Studi Kasus : Universitas Pasir Pengaraian). Riau Journal Of Computer Science, 4(1), 129-143.

Ferdinandus, S., Wowor, H., \& Lumenta, A. (2012). Perancangan Aplikasi Surat Masuk dan Surat Keluar pada PT. PLN (Persero) Wilayah Suluttenggo. Jurnal Teknik Elektro-FT, 1(1), 1-7.

Hanifah, U., Alit, R., \& Sugiarto. (2016). Penggunaan Metode Black Box pada Pengujian Sistem Informasi Surat Keluar Masuk. SCAN, 11(2), 33-40.

Hidayat, T., \& Muttaqin, M. (2018). Pengujian Sistem Informasi Pendaftaran dan Pembayaran Wisuda Online Menggunakan Black Box Testing dengan Metode Equivalence Partitioning dan Boundary Value Analysis. Jurnal Teknik Informatika UNIS (JUTIS), 6(1), 25-29.

Komarudin, M. (2016). Pengujian Perangkat Lunak Metode Black-Box Berbasis Equivalence Partitions pada Aplikasi Sistem Informasi Sekolah. Jurnal Manajemen Infromatika (MIKROTIK), 6(3), 1-18.

Lumbanraja, H. D. (2017). Perancangan Sistem Informasi Akademik Online Menggunakan Black Box Testing pada Sekolah Tinggi Ilmu Ekonomi Surya Nusantara. Jurnal Akuntansi dan Manajemen (Jurakunman), 2(7), 1-11.

Mustaqbal, M. S., Firdaus, R. F., \& Rahmadi, H. (2015). Pengujian Aplikasi Menggunakan Black Box Testing Boundary Value Analysis (Studi Kasus : Aplikasi Prediksi Kelulusan SNMPTN). Jurnal Ilmiah Teknologi Informasi Terapan (JITTER), 1(3), 31-36.

Nursetyo, G. (2016). Kajian Permainan dalam Aturan Lelang Proyek. Jurnal Teknik Sipil dan Arsitektur (JTSA), 19(23), 1-10.

Syaban, R. M., \& Syaban, H. (2015). Pengembangan Sistem Informasi Surat Masuk dan Surat Keluar Berbasis Web di Dinas Sosial Tenaga Kerja dan Transmigrasi Kabupaten Garut Menggunakan Framework PHP. Jurnal Algoritma Sekolah Tinggi Teknologi Garut, 12(1), 1-11. 